\title{
Análisis del despido nulo ex Art. 55.5 ET*
}

\author{
Analysis about null dismissal ex Art. 55.5 ET
}

\author{
Raquel Poquet Catala* \\ Universidad de Valencia \\ ORCID ID: 0000-0001-9606-8832
}

Recibido: 03/05/2020

Aceptado: 02/09/2020

doi: https://doi.org/10.20318/femeris.2020.5764

\begin{abstract}
Resumen. En este trabajo se realiza un análisis de la configuración jurídica de la institución recogida en el art. 55.5 ET en relación con la declaración automática de nulidad de los despidos que tengan como móvil alguno de los supuestos relacionados en sus letras a), b) o c), esto es, relativos a la conciliación de la vida familiar y laboral, tanto desde el punto de vista de su conceptuación como nulidad objetiva -sin necesidad de comunicación expresa al empresario-, como desde el punto de vista de su extensión temporal de protección. Para ello, se analiza, en primer lugar, la normativa, tanto a nivel internacional, comunitario y nacional. A continuación, se examina su ámbito de protección, centrándonos en el análisis de la doctrina tanto judicial, jurisprudencial como constitucional. Por último, se realiza un estudio del ámbito temporal de protección teniendo en cuenta los pronunciamientos judiciales.

Palabras clave: despido, nulidad, embarazo, maternidad, trabajadora

Abstract. In this work it is carried out an analysis of the legal configuration of the institution included in art. 55.5 ET in relation to the automatic declaration of nullity of dismissals that have as a motive of the assumptions related in its letters a), b) or c), that is, related to the conciliation of family and work life, both from the point of view of its conceptualization as objective nullity -without the need for express communication to the employer-, as from the point of view of its temporary extension of protection. To do this, firstly, it is analyzed the regulation, both at international, community and national levels. Next, it is examined its scope of protection, focusing on the analysis of both judicial, jurisprudential and constitutional doctrine. Finally, it is carried out a study of the temporal scope of protection, taking into account the judicial pronouncements.
\end{abstract}

Keywords: dismissal, nullity, pregnancy, maternity, worker.

"Este trabajo ha sido realizado en el ámbito del proyecto de investigación del programa "Retos Investigación 2018" del Ministerio de Ciencia, Innovación y Universidades, "Análisis jurídico y sociológico de las brechas de género en las transiciones trabajo-jubilación-trabajo: factores de la desigualdad y propuestas normativas".

**raquel.poquet@uv.es 


\section{Introducción}

El progreso habido en el S. XX y en los inicios de este S. XXI no sería explicable sin la búsqueda del valor de la igualdad de hombres y mujeres. Por tanto, frente a la tradicional idea -que hoy nos parece totalmente rechazable- de que la mujer queda sometida al hombre, idea basada en la concepción de que la mujer es física y moralmente débil frente al hombre, ha ido surgiendo una corriente que ha ido cambiando esta concepción de la posición de la mujer, iniciándose en un primer momento en el ámbito del Derecho civil, hasta llegar al área del Derecho del Trabajo ${ }^{1}$.

No obstante, a pesar de ello, aún se observa como en el entorno laboral para muchas empresas la maternidad y la atención y el cuidado de los menores no es compatible con el trabajo. De ahí, el recurso a las rescisiones de los contratos de aquellas trabajadoras que se sospeche que puedan o tengan intención de quedar embarazadas ${ }^{2}$.

En este sentido, debe recordarse la doctrina constitucional de que "ni las organizaciones empresariales forman mundos separados y estancos del resto de la sociedad ni la libertad de empresa que establece el art. 38 del texto constitucional legitima el que quienes prestan servicios en aquélla por cuenta y bajo la dependencia de sus titulares deban soportar despojos transitorios o limitaciones injustificadas de sus derechos fundamentales y libertades públicas, que tienen un valor central y nuclear en el sistema jurídico constitucional. Las manifestaciones de "feudalismo industrial" repugnan al Estado social y democrático de Derecho y a los valores superiores de libertad, justicia e igualdad"3.

En definitiva, a pesar de encontrarnos en el S. XXI, y aunque se pueda pensar que se han producido grandes avances en materia de derechos laborales, la realidad nos muestra todo lo contrario. Uno de estos graves desajustes se halla en la pérdida de empleo tras la maternidad. A pesar de que el art. 55 ET, en sus diferentes modificaciones y reformas, apuesta por ofrecer un blindaje absoluto al despido de las mujeres trabajadoras por cuestiones relacionadas con la conciliación de la vida laboral y familiar, perviven situaciones donde se trata de sortear esta tutela, como puede ser la estrategia de despedir a la persona trabajadora después de su reincorporación al puesto de trabajo con motivo de la finalización del ejercicio de los derechos de conciliación de la vida personal, familiar y laboral.

\footnotetext{
${ }^{1}$ STSJ Madrid, de 28 de noviembre de 2014, rec. núm. 678/2014. Concretamente, señala que "“'se ha ido abriendo una importante corriente o reacción cultural de la sociedad, inicialmente minoritaria, refrendada por el Derecho, que ha cambiado la posición de la mujer en su posición civil dentro del matrimonio, la política (derecho al voto de las mujeres que supuso una de sus grandes conquistas), en la contratación y, finalmente, en el trabajo".

${ }^{2}$ ARAMENDI SÁNCHEZ, Pablo (2006) El despido de la trabajadora embarazada. Un análisis de la Sentencia de 19 de julio de 2007 del Pleno de la Sala IV Tribunal Supremo, AS, núm. 13 (versión on line). Literalmente indica que "es una realidad que maternidad y trabajo resultan incompatibles para muchos empresarios, sobre todo del sector privado, lo que les mueve a intentar desprenderse de la trabajadora cuando saben o sospechan de su estado de gravidez pues ello conllevará más adelante bajas por maternidad, posibles solicitudes de reducción de jornada, ocasionales bajas médicas durante el embarazo, eventuales ausencias al trabajo por cuidado de hijos etcétera".

${ }^{3}$ STC 88/1985, de 19 de julio.
} 


\section{Marco jurídico aplicable}

\subsection{Derecho internacional y comunitario}

En el ámbito internacional, la nulidad de los despidos que tengan su causa en la discriminación por razón de sexo se contempla en diversos convenios de la OIT. Así, el Convenio núm. 3 OIT, de 29 de octubre de 1919, relativo al empleo de las mujeres antes y después del parto, señala en su art. 4 que tanto durante el período de descanso voluntario previo como durante el período de descanso obligatorio posterior al parto, e incluso durante un período posterior de ausencia al trabajo por enfermedad consecuencia del embarazo o parto "será ilegal que, hasta que su ausencia haya excedido de un período máximo fijado por la autoridad competente de cada país, su empleador le comunique el despido durante dicha ausencia o se lo comunique de suerte que el plazo estipulado en el aviso expire durante la mencionada ausencia".

Así también el Convenio núm. 103 OIT, de 28 junio 1952, relativo a la protección de la maternidad, establece en su art. 6 que cuando una mujer se encuentre ausente de su trabajo como consecuencia del disfrute del descanso por maternidad, del descanso prenatal suplementario o del descanso puerperal, será ilegal que su empleador le comunique su despido, o que la comunicación llegue a su conocimiento en fecha tal que el plazo de preaviso expire durante la mencionada ausencia. Por su parte, el Convenio núm. 156 OIT, de 23 de junio de 1981, sobre la igualdad de oportunidades y de trato entre trabajadores y trabajadoras: trabajadores con responsabilidades familiares, prevé en su art. 8 que "la responsabilidad familiar no debe constituir de por sí una causa justificada para poner fin a la relación de trabajo". El Convenio núm. 158 OIT, de 22 de junio de 1982, sobre la terminación de la relación de trabajo por iniciativa del empleador, incluye en su art. 5, en concreto en la letra e), "la ausencia del trabajo durante la licencia de maternidad" entre los motivos que no constituyen causa justa para la terminación de la relación de trabajo ${ }^{4}$. Destaca también el Convenio núm. 183 OIT, de 30 de mayo de 2000, sobre la protección de la maternidad, que prohíbe a la empresa que despida a una mujer que esté embarazada, durante la licencia por maternidad, o después de haberse reintegrado al trabajo durante un periodo que ha de determinarse en la legislación nacional. No obstante, no es una prohibición absoluta, pues, lógicamente, podrá hacerlo por motivos que no estén relacionados con el embarazo, el nacimiento del hijo y sus consecuencias o la lactancia.

A nivel comunitario fue, en primer lugar, la Directiva 76/207/CEE ${ }^{5}$, la que reguló de forma expresa el principio de igualdad de trato entre hombres y mujeres en el ámbito laboral, prohibiendo todo tipo de discriminación, tanto la directa como la indirecta.

${ }^{4}$ ARGÜELLES BLANCO, Ana Rosa (1998) La protección de intereses familiares en el ordenamiento laboral. Valencia: Tirant lo Blanch, 1998. p. 89-90; DE LA VILLA GIL, Luis Enrique; GARCÍA NINET, Ignacio; NOGUEIRA GUASTAVINO, Magdalena; MORÓN PRIETO, Ricardo; DE LA VILLA DE LA SERNA, Diego (1998),Leyes Sociales Internacionales y Comunitarias. Madrid: CEURA. p. 23 y ss.

${ }^{5}$ De 9 de febrero, relativa a la aplicación del principio de igualdad de trato entre hombres y mujeres en lo que se refiere al acceso al empleo, a la formación y a la promoción profesionales, y a las condiciones de trabajo. 
Sin embargo, es la Directiva 92/85/CEE ${ }^{6}$ la que establece una prohibición general, y casi incondicionada, de despedir durante las situaciones de embarazo, parto y lactancia ${ }^{7}$, pues su art. 10 titulado "prohibición de despido" prevé la posibilidad de que, como garantía para las trabajadoras del ejercicio de sus derechos, de "protección de su seguridad y salud", los Estados miembros adopten las medidas necesarias para prohibir el despido durante el período comprendido desde el comienzo del embarazo hasta el final del permiso por maternidad. Como se observa, este precepto introduce literalmente el término "prohibir" el despido, lo cual significa que no será válido aquel despido producido durante el período que se extiende desde el inicio de la gestación hasta el final del permiso de maternidad, salvo, obviamente, aquellos casos fundamentados en una causa objetiva, justificada y regulada por la correspondiente legislación nacional.

Esta prohibición de despido se configura casi como "incondicionada", por lo que las posibles excepciones a esta regla deben ser interpretadas de forma muy restrictiva, pues así debe deducirse del apartado 2 del citado art. 10 cuando señala que "el empresario deberá dar motivos justificados de despido por escrito". Por tanto, no será suficiente con alegar cualquier motivo de extinción del contrato. De hecho, la doctrina judicial comunitaria considera que el hecho de autorizar excepciones a la prohibición de despido de las trabajadoras durante dicho período no obliga a los Estados miembros a especificar las causas de despido de dichas trabajadoras, pues la directiva no obliga a los Estados miembros a elaborar una lista especial de motivos de despido que serán admitidos como causas justificativas. Además, no parece consecuente que deba propiciarse una lista cerrada de causas, pues lo será, en toda su extensión, cualquiera que no esté involucrado en la situación de embarazo o maternidad ${ }^{8}$. En definitiva, ello significa que no existe una prohibición absoluta e incondicionada de despido de una trabajadora durante el disfrute de los derechos relacionados con la maternidad, sino que si concurre alguna de las causas del art. 49 ET, siendo las mismas objetivas y justificadas, el despido será procedente.

En este sentido, debe aludirse a que la protección de la Directiva 92/85/CEE alcanza al despido improcedente que pudiera acaecer cuando, sin acreditarse la discriminación, no se pruebe por la empresa que concurre una causa lícita y probada para el despido.

Además, el Informe de la Comisión de 15 de marzo de 1999 sobre la aplicación de la Directiva 92/85/CEE, señalaba que si se despide a una mujer durante el embarazo o el permiso por maternidad, la mayoría de los Estados miembros exigen que la empresa demuestre que el despido se debe a una causa objetiva al margen del embarazo, y el citado art. 10

${ }^{6}$ De 19 de octubre, relativa a la aplicación de medidas para promover la mejora de la seguridad y de la salud en el trabajo de la trabajadora embarazada, que haya dado a luz o en período de lactancia.

${ }^{7}$ MOLINA GONZÁLEZ-PUMARIEGA, Rocío (2004), La protección jurídica de la mujer trabajadora. Madrid: CES. p. 291. Vid CORDERO SAAVEDRA, Luciano (2002), La protección de las mujeres embarazadas contra el despido y aplicación de las directivas 76/207/CEE Y 92/85/CEE (A propósito de la STJCE 4 de octubre de 2001), Aranzadi Social, núm. 5, 2002, p. 685-694; MAZUELOS FERNÁNDEZ-FIGUEROA, Manuel (2002), Alcance del efecto directo del artículo 10 de la directiva 92/85/CEE ante el incumplimiento de un Estado miembro: Crónica de una cuestión prejudicial: protección del despido de las mujeres embarazadas y la sentencia del Tribunal de Justicia de 4 de octubre de 2001, Actualidad Jurídica Aranzadi, núm. 520, 2002, p. 1-8.

${ }^{8}$ NÚÑEZ-CORTÉS CONTRERAS, Pilar (2017), La maternidad. Nuevas realidades en el Derecho de la Unión Europea. Madrid: Dykinson. p. 77. 
establece la prohibición de despedir a las mujeres trabajadoras comprendidas en su ámbito durante el período que se extiende desde el inicio del embarazo hasta la finalización del permiso por maternidad, con la salvedad del despido por razones ajenas al embarazo.

La doctrina judicial comunitaria ${ }^{9}$ atribuye efecto directo al art. 10 considerando que si un Estado miembro no ha adoptado medidas correspondientes en su Derecho interno en el plazo señalado por la Directiva, confiere a los particulares derechos que estos pueden invocar ante un órgano judicial nacional. Además, estima que el citado precepto no debe interpretarse en el sentido de que impone a los Estados miembros la obligación de prever la intervención de una autoridad nacional que, tras comprobar la concurrencia de circunstancias excepcionales que pueden justificar el despido de una de estas trabajadoras, otorgue su acuerdo previo a la decisión de la empresa al respecto. Es decir, la obligación de adoptar "las medidas necesarias para prohibir el despido de las trabajadoras, a que se refiere el artículo 2, durante el período comprendido entre el comienzo de su embarazo y el final del permiso de maternidad a que se refiere el apartado 1 del artículo 8", se impone de forma incondicional y se define con claridad y precisión, tanto por lo que se refiere a su objeto (prohibición de despido) como a los sujetos protegidos (las trabajadoras que, a los efectos del artículo 2 de la Directiva y de conformidad con las legislaciones y/o las prácticas nacionales, hayan informado de su estado al empresario) y al período que ha de tomarse en consideración (la prohibición de despido cubre un período de tiempo que puede determinarse con precisión, partiendo de la fecha en que comienza el embarazo hasta el final del permiso de maternidad a que se refiere el artículo 8, apartado 1).

También deben citarse otras Directivas comunitarias en esta materia que se centran en evitar situaciones discriminatorias, como la 2000/43/CE, o la 2000/78/CE, instrumentos que prohíben los actos de discriminación en el empleo, incluyendo los despidos discriminatorios por razón de sexo, origen racial o étnico, religión o convicciones, discapacidad, edad u orientación sexual.

Posteriormente, la Directiva 2006/54/CE, 5 de julio de 2006, relativa a la aplicación del principio de igualdad de oportunidades e igualdad de trato entre hombres y mujeres en asuntos de empleo y ocupación (refundición), dedica varios de sus preceptos a garantizar y proteger el principio de igualdad en la dinámica de la relación laboral, concretamente en sus arts. 4 y 14.1. En la letra c) del art. 14.1 el precepto extiende la prohibición de discriminación a las condiciones "de despido", sin más consideraciones, por lo que debemos entender que el precepto se refiere a cualquier actuación discriminatoria que tenga referencia con la figura del despido, incluyendo todas las modalidades de despido, tanto el que responda a un carácter disciplinario, como las modalidades extintivas de carácter objetivo incluido el despido colectivo ${ }^{10}$.

${ }^{9}$ STJUE de 4 de diciembre de 2001, C-738/1999, asunto Jiménez Melgar. En el mismo sentido, SSTJUE de 26 de febrero de 2008, C-506/2006, asunto Mayr; de 11 de octubre de 2007, C-460/2006, asunto Paquay; de 20 de junio de 2013, C-259/2012, asunto Nadezda Riezniece; de 19 de septiembre de 2013, C-5/2012, asunto Marc Betriu; de 20 de junio de 2013, C-7/2012, asunto Nadezda Riezniece;

${ }^{10}$ Cabe tener en cuenta la STJUE de 22 de febrero de 2018, C-103/2016, Asunto Porras Guisado, que no estima esa nulidad automática. 


\subsection{Derecho nacional}

En cuanto a la normativa nacional, en cumplimiento de este mandato comunitario, se aprueba la Ley 39/1999, de 5 de noviembre, para promover la conciliación de la vida familiar y laboral de las personas trabajadoras, la cual responde, básicamente a dos necesidades. Por un lado, a la exigencia de adaptar las normas a los cambios sociales consecuencia de la significativa incorporación de la mujer al mercado de trabajo; y, por otro lado, a la necesidad de adecuar las normas internas a las directrices internacionales y comunitarias preocupadas por fomentar un reparto equilibrado de tareas entre hombres y mujeres y por facilitar la conciliación entre responsabilidades familiares y profesionales $^{11}$.

Ya, en su Exposición de Motivos, la Ley 39/1999 indicaba que, "como consecuencia de la constatación de una evidente realidad social y de la valoración global de los cambios sociales efectivamente constatados a raíz de la incorporación masiva de la mujer al trabajo se toma conciencia de la necesidad de configurar un nuevo sistema de relaciones de trabajo que atienda, no sólo a las necesidades nacidas como consecuencia de las nuevas relaciones sociales surgidas, sino también a un nuevo modo de cooperación y compromiso entre mujeres y hombres que permita un reparto equilibrado de responsabilidad en la vida profesional y familiar".

La citada norma introduce en nuestro ordenamiento diversos supuestos de despido nulo vinculados con el embarazo y maternidad de la trabajadora y con la conciliación de la vida laboral y familiar ${ }^{12}$. Por un lado, el despido de las trabajadoras embarazadas, desde la fecha del inicio del embarazo hasta la del comienzo del período de suspensión por maternidad, riesgo durante el embarazo, adopción o acogimiento, o el notificado en fecha tal que el plazo de preaviso finalice dentro de dicho período. Por otro lado, el despido de los trabajadores con contrato suspendido por alguno de los motivos antes indicados o el notificado en fecha tal que el plazo de preaviso finalice dentro de dicho período. Y, por último, se declara nulo el despido de los trabajadores, que hayan solicitado o estén disfrutando de los permisos a que se refieren los apartados 4 y 6 del artículo 37 ET, esto es, el permiso de

\footnotetext{
${ }^{11}$ LOUSADA AROCHENA, José Fernando (2000) Las novedades en el régimen de los permisos parentales introducidos en la Ley 39/1999, de 5 de noviembre, $A L$, núm. 25. p. 441.

${ }^{12}$ Como indica la doctrina judicial, STSJ País Vasco, de 5 de febrero de 2019, rec. núm. 74/2019 "recordar que la Ley 39/1999, de 5 de noviembre, de conciliación de la vida familiar y laboral de las personas trabajadoras, introdujo en nuestro ordenamiento jurídico laboral una nueva categoría de despidos nulos, como medida de máxima eficacia para lograr la adecuada protección de los trabajadores y trabajadoras en situación de ejercer alguno de los derechos reconocidos en esa Ley para conciliar la vida familiar y laboral. Categoría distinta a la de los despidos nulos existentes hasta entonces, determinados por obedecer a un móvil discriminatorio o producirse con violación de los derechos fundamentales o libertades públicas del despedido, según disponía el art. 55.5 del vigente texto refundido del Estatuto de los Trabajadores. Cierto es que con la nueva categoría, en su mayor parte, se protegía a las trabajadoras en situación de embarazo o de disfrute de derechos vinculados a su reciente maternidad y que, con ello, se mejoraba la protección de quienes, por esas circunstancias, estaban en situación proclive a que su despido obedeciera a un móvil discriminatorio, pero su finalidad no es ésa sino la de salvaguardar los derechos destinados a conciliar la vida familiar con la laboral y, aunque ciertamente, se convierte en medida muy útil para mejorar la protección contra la prohibición de discriminación por razón de sexo, en sutil paradoja, se hacía configurando una causa de nulidad del despido desvinculada de ese móvil, de tal forma que operase cuando concurrieran las circunstancias determinantes de esa nulidad (causa extintiva aducida por el empresario sin fundamento legal y situación de embarazo o disfrute de alguno de esos derechos), incluso aunque se demostrase que el móvil empresarial era bien ajeno a la discriminación prohibida".
} 
lactancia y la reducción de jornada por guarda legal o cuidado de familiares, y el despido de los trabajadores que hayan solicitado la excedencia por cuidado de hijos o familiares a que se refiere el artículo $46.3 \mathrm{ET}$.

Sin embargo, la señalada adaptación no fue adecuada, pues la Ley 39/1999 realizó una transposición implícita de la prohibición de despido, sin aprovechar el momento para llevar a cabo una clara y expresa formulación de las previsiones del señalado art. 10 Directiva en nuestro $\mathrm{ET}^{13}$.

Posteriormente, la LO 3/2007, de 22 de marzo, para la igualdad efectiva de mujeres y hombres, mejora el ámbito protector ampliando el elenco de causas que conllevan la declaración de nulidad del despido, como los períodos de suspensión del contrato de trabajo por paternidad, riesgo durante la lactancia natural y enfermedades causadas por embarazo, parto o lactancia natural; o el período de solicitud y disfrute del permiso o reducción de jornada por nacimiento de hijos prematuros o que por cualquier circunstancia tengan que permanecer hospitalizados a continuación del parto, así como el período de disfrute, y no sólo de solicitud, de la excedencia del artículo 46.3 ET por cuidado de hijos o familiares. También se protege el despido de las trabajadoras víctimas de violencia de género, cuando éste tenga su origen en el ejercicio de los derechos de reducción o reordenación de su tiempo de trabajo, de movilidad geográfica, de cambio de centro de trabajo o de suspensión de la relación laboral. Por último, quedan también protegidos los trabajadores después de haberse reintegrado al trabajo al finalizar los períodos de suspensión del contrato por maternidad, adopción o acogimiento o paternidad, siempre que no hubieran transcurrido más de nueve meses desde la fecha de nacimiento, adopción o acogimiento del hijo ${ }^{14}$.

${ }^{13}$ MAZUELOS FERNÁNDEZ-FIGUEROA, Manuel (2002), Alcance del efecto directo del artículo 10 de la directiva 92/85/CEE ante el incumplimiento de un Estado miembro. Crónica de una cuestión prejudicial: protección del despido de las mujeres embarazadas y la sentencia del Tribunal de Justicia de 4 de octubre de 2001, Actualidad Jurídica Aranzadi, núm. 520, 2002.

${ }^{14}$ Un resumen de esta evolución normativa la realiza la STSJ País Vasco, de 13 de marzo de 2018, rec. núm. 194/2018, cuando declara que "y es que para valorar las posibles conductas discriminatorias por razón de sexo (género) y ponderar las exigencias de nuestro principio de igualdad del art. 14 de la CE (...), cuya muestra es la Ley Orgánica 3/07 para la igualdad efectiva de mujeres y hombres, y también las múltiples reformas normativas afectantes a los preceptos del ET reguladores del despido, y su calificación como nulo si existe un móvil discriminatorio por razón del estado de embarazo de la trabajadora o del momento en que se produce la extinción en relación con la gestación, pero también en otros supuestos que queremos reseñar, de suspensión por guarda, reducciones de jornada, de menores, familiares y vinculaciones derivadas de los ámbitos de maternidad, paternidad, adopción o acogimiento, que se enmarcan en el halo protector de la discriminación, que nos llevarán, en el caso de autos, a la alusión ineludible, jurídica y judicialmente, de que el supuesto de embarazo ectópico, queda relacionado con esta constante de protección.

Recordar que la Ley 39/1999, de 5 de noviembre, de conciliación de la vida familiar y laboral de las personas trabajadoras, introdujo en nuestro ordenamiento jurídico laboral una nueva categoría de despidos nulos, como medida de máxima eficacia para lograr la adecuada protección de los trabajadores y trabajadoras en situación de ejercer alguno de los derechos reconocidos en esa Ley para conciliar la vida familiar y laboral. Categoría distinta a la de los despidos nulos existentes hasta entonces, determinados por obedecer a un móvil discriminatorio o producirse con violación de los derechos fundamentales o libertades públicas del despedido, según disponía el art. 55.5 del vigente texto refundido del Estatuto de los Trabajadores (ET). Cierto es que con la nueva categoría, en su mayor parte, se protegía a las trabajadoras en situación de embarazo o de disfrute de derechos vinculados a su reciente maternidad y que, con ello, se mejoraba la protección de quienes, por esas circunstancias, estaban en situación proclive a que su despido obedeciera a un móvil discriminatorio, pero su finalidad no es ésa sino la de salvaguardar los derechos destinados a conciliar la vida familiar con la laboral y, aunque ciertamente, se convierte en medida muy útil para mejorar la protección contra la prohibición de discriminación por razón de sexo, en sutil paradoja, se hacía configurando una causa de nulidad del despido desvinculada de ese móvil, de tal forma que operase cuando concurrieran las circunstancias determinantes de esa nulidad". 
Por último, el RDL 6/2019, de 1 de marzo, de medidas urgentes para garantía de la igualdad de trato y de oportunidades entre mujeres y hombres en el empleo y la ocupación, a la vez que actualiza los supuestos comprendidos, amplia el periodo de protección de la nulidad objetiva de nueva doce meses tras la reincorporación de la madre trabajadora.

De cualquier forma, el elemento central lo constituye el art. 55.5 ET que establece la nulidad de aquellos despidos relacionados con la maternidad o la conciliación de la vida personal y familiar. Esta protección del art. 55.5 ET "se orienta en proporcionar a la trabajadora (y también en algunos casos al trabajador), una tutela judicial efectiva más enérgica que la actual y ordinaria en el ámbito de la discriminación genérica, por cuanto, en general, se dispensa la carga de prueba y acreditación de indicios, sobre la conculcación del derecho fundamental a la igualdad u otros, eximiendo de prueba no ya solo respecto del conocimiento o no de determinadas circunstancias como el embarazo, que todo hay que decirlo, se circunscribe al ámbito más interno, íntimo, privado y de dignidad, como ya hemos venido a manifestar expresamente en nuestra sentencia de 6-9-16, recurso 1456/16, en el estudio de una sanción por falta grave con alusión al deber de lealtad de la trabajadora, la inexigencia de comunicación al empleador de su embarazo al afectar a su derecho a la intimidad, de manera ineludible. Con ello, se ha corregido jurisprudencialmente no solo esa imagen atentatoria contra la dignidad de la mujer, sino también las dificultades probatorias de acreditación de las circunstancias del conocimiento empresarial"15.

Concretamente, el art. 55.5.2 b) ET protege el ejercicio de los derechos de conciliación de la vida laboral y familiar, que, según la jurisprudencia ${ }^{16}$, se trata de una "causa de nulidad, distinta de la nulidad por causa de discriminación". Con ella, el legislador ha configurado una garantía de tutela efectiva frente al riesgo de despido por embarazo de naturaleza "automática".

En relación con esta institución protectora se plantean, a mi modo de ver, dos interrogantes clave. Por un lado, el ámbito de protección desde el punto de vista subjetivo, esto es, si, para que la declaración de nulidad sea operativa es suficiente la constatación del estado del embarazo, y, por otro lado, la extensión temporal del ámbito de protección, esto es, cuál es el período que abarca dicha prohibición de despido.

\section{Efectividad de la protección}

Cuando nos referimos a la efectividad de este mecanismo protector, se trata de analizar si es necesario que el empresario tenga conocimiento del estado de gestación de la trabajadora para que pueda apreciarse la nulidad (configuración subjetiva) o, por el contrario, es suficiente la constatación del estado de embarazo (configuración objetiva).

\footnotetext{
${ }^{15}$ STSJ País Vasco, de 13 de marzo de 2018, rec. núm. 194/2018.
}

${ }^{16}$ STS, $4 .{ }^{\text {a }}$, de 14 de enero de 2015 , rec. $104 / 2014$ 


\subsection{Concepción subjetiva}

Dentro de los que han abogado por la concepción subjetiva se halla, por un lado, nuestro alto tribunal, el cual, en una primera fase evolutiva, y con el fin de unificar criterios, dicta sendas sentencias en $2006^{17}$, en las que aboga por la tesis subjetiva. Para ello, se apoya en el criterio teleológico, de tal forma que la clave se halla en la finalidad perseguida con la introducción de este supuesto de nulidad en el artículo 55.5 del ET. Considera el TS que la Ley 39/1999 "concibe dicha calificación como un supuesto particular de «despido discriminatorio», esto es, de despido nulo por lesión de derechos fundamentales, en el que el derecho fundamental lesionado es el derecho a no ser discriminado por razón de sexo o por razón de cargas familiares". Asimilación declarada, en su opinión, en la Exposición de Motivos de la Ley 39/1999 cuando se afirma que "el último artículo del Capítulo I prevé las modificaciones que han de realizarse en el Estatuto de los Trabajadores relativas a la extinción del contrato de trabajo. Para ello se declara expresamente nula (en la nueva redacción del art. 55.5. ET) la decisión extintiva o el despido motivado, entre otros, por el embarazo".

El Tribunal Supremo añade además a esta configuración subjetiva de la nulidad que no se exige "comunicación" alguna al empresario del estado de embarazo, siendo suficiente que éste tenga conocimiento de dicha circunstancia, ya sea porque sea apreciable a simple vista, o bien por el hecho de que sea conocido en el centro de trabajo.

En un segundo momento, el $\mathrm{TS}^{18}$ añade que el legislador podría haber aprovechado la reforma legislativa para introducir modificaciones en la regulación de la nulidad de la trabajadora embarazada y, sin embargo, no se ha producido alteración alguna al respecto encaminada a poder aclarar la cuestión litigiosa, lo cual revela que no se aprecia una discordancia entre la voluntad legislativa y la labor interpretativa desarrollada por el TS.

Además, refuta el argumento relativo a la inexigibilidad de la comunicación del estado de gestación al empleador amparada en la superación por parte de la Ley 39/1999 de los niveles mínimos de protección previstos en la Directiva 92/85/CEE. Considera que "en buena hermenéutica, la referencia a los «niveles mínimos de protección» que efectúa la exposición de motivos de la Ley 39/1999, lleva a entender que con esa expresión el legislador se está refiriendo a las previsiones de las Directivas traspuestas que contienen reglas de protección «mínimas», es decir, aquellas que establecen un umbral que puede ser superado". Y partiendo de esta premisa considera que entre las reglas que establecen mínimos superables por las legislaciones nacionales "no se encuentra evidentemente el art. 2 de la Directiva, que no es un precepto que establezca mínimos, sino que contiene una simple definición a efectos de una protección uniforme". Asimismo, vuelve a recordar que es cierto que nuestro ordenamiento "no exige la «comunicación» al empresario del estado de embarazo", pero advierte que de dicho silencio no se puede deducir la intención del legislador de introducir un supuesto de nulidad objetiva, sobre todo a la vista de "los argumentos de la exposición de motivos de la Ley 39/1999 y el contenido de los preceptos sustantivos y procesales”.

\footnotetext{
${ }^{17}$ SSTS (dos), de 19 de julio de 2006, rec. núm. 387/2005 y 1452/2005.

${ }^{18}$ SSTS de 29 de febrero de 2008, rec. núm. 657/2007; de 12 de marzo de 2008, rec. núm. 1695/2007.
} 
En el mismo sentido, se ha inclinado un sector de la doctrina judicial, considerando que se trata de un supuesto de discriminación por razón de sexo, sin efectuar referencia alguna a la modificación legislativa sobre la materia introducida por la Ley 39/199919.

\subsection{Concepción objetiva}

Entre los que han optado por la configuración objetiva, debe destacarse el TC, quien desde el primer momento se ha mantenido en esta postura. En STC 92/2008, de 21 de julio, aclara, por un lado, que el despido basado en el embarazo de una trabajadora constituye una discriminación por razón de sexo. A continuación, retoma el debate en relación al conocimiento o no por la empresa de la situación de embarazo para declarar que "difícilmente puede apreciarse la existencia de un tratamiento peyorativo basado en el embarazo de la trabajadora cuando no haya quedado acreditado el conocimiento por la empresa de dicho embarazo o de cualquier otra situación o circunstancia que pudiera entenderse conectada con el mismo, ni existan otros datos de los que, pese a la falta de constancia expresa del conocimiento, pueda deducirse la probabilidad de la lesión"20.

Por tanto, considera que no cabe apreciar discriminación por razón de sexo al exigir el conocimiento empresarial del embarazo para calificar como nulo el despido de una trabajadora embarazada.

Además, considera que en aplicación de los criterios de interpretación de las normas -criterio gramatical, lógico y teológico- permite concluir que la nulidad del despido tiene un carácter automático y objetivo, desvinculado de la acreditación del estado de gestación ${ }^{21}$.

El TC apunta hacia la "necesaria finalidad de innovación del ordenamiento jurídico que debe perseguir toda reforma legal" en pro de la concepción objetiva, porque la innovación frente a la regulación anterior se residencia en la no exigencia del conocimiento empresarial del estado de gestación de la trabajadora.

Además, declara que "la regulación legal de la nulidad del despido de las trabajadoras embarazadas constituye una institución directamente vinculada con el derecho a la no discriminación por razón de sexo proclamado en el art. $14 \mathrm{CE}$, por más que puedan igualmente hallarse vínculos de la misma con otros derechos y bienes constitucionalmente protegidos: así, con el derecho a la seguridad y la salud de las trabajadoras embarazadas, por cuya garantía deben velar los poderes públicos conforme al art. 40.2 CE (...) que constituye particularmente el fundamento de la regulación establecida en la Directiva 92/85/ CEE; o con el aseguramiento de la protección de la familia y de los hijos al que se refieren los apartados 1 y 2 del art. 39 CE"22.

\footnotetext{
${ }^{19}$ SSTSJ Cantabria, de 15 de octubre de 2001, rec. núm. 749/2001; Andalucía, de 8 de enero de 2003, rec. núm. 2350/2002; Aragón, de 18 de junio de 2003, rec. núm. 417/2003; Comunidad Valenciana, de 17 de diciembre de 2004, rec. núm. $3227 / 2004$.

${ }^{20}$ STC 92/2008, de 21 de julio.

${ }^{21}$ GIL PLANA, Juan (2012) “La nulidad del despido de la trabajadora embarazada”, REDT, núm. 154 (versión on line)

${ }^{22}$ STC 92/2008, de 21 de julio.
} 
Posteriormente, el TC ${ }^{23}$ vuelve a confirmar esta concepción objetiva de la nulidad del despido de una trabajadora embarazada, y además desde la óptica de la discriminación por razón de sexo. Esta sentencia contiene un voto particular formulado por el Magistrado don Vicente Conde Martín de Hijas en el que se considera que, si la clave para la resolución de la cuestión controvertida está dentro de la órbita de la discriminación, no es aceptable que pueda ser compatible imputar a alguien una conducta discriminatoria y que éste desconozca el hecho o factor de discriminación que se le imputa. Afirma que "la idea de discriminación exige con lógica naturalidad el conocimiento del hecho al que se refiere la discriminación, y por ello no creo que pueda hablarse correctamente de despido «motivado por el embarazo», si el embarazo no se conoce".

En cuanto al TS, tras estos pronunciamientos constitucionales, cambia su anterior línea ${ }^{24}$ y opta también por una concepción objetiva de la nulidad del despido de la trabajadora embarazada, acomodando así su criterio a la doctrina constitucional. Y esa es la línea que ha venido manteniendo a lo largo de estos años ${ }^{25}$, al señalar que "la finalidad de la norma es proporcionar a la trabajadora embarazada una tutela más enérgica que la ordinaria frente a la discriminación, dispensándola de la carga de acreditar indicio alguno sobre la conculcación del derecho fundamental y eximiéndola de probar que el empresario tenía conocimiento del embarazo; cuestión ésta que pertenece a la esfera más íntima de la persona y que la trabajadora puede desear mantener -legítimamente- preservado del conocimiento ajeno; (...) Todo ello lleva a entender que el precepto es "configurador de una nulidad objetiva, distinta de la nulidad por causa de discriminación contemplada en el párrafo primero y que actúa en toda situación de embarazo, al margen de que existan o no indicios de tratamiento discriminatorio o, incluso, de que concurra o no un móvil de discriminación»".

Por su parte, respecto de la doctrina judicial, aunque, como se ha indicado, un sector -minoritario- apostó por la concepción subjetiva, la mayoría entiende que debe seguirse el criterio objetivo, pues considera que el supuesto de nulidad introducido por la Ley 39/1999 era la trasposición del Derecho comunitario y debía, en consecuencia, interpretarse conforme a la correspondiente jurisprudencia comunitaria, por lo que si la Ley 39/1999 “omite esa definición (...) se ha de entender que el criterio legal es el de no exigir a la mujer trabajadora que comunique su estado al empresario, permaneciendo el embarazo en el ámbito del derecho a la intimidad de la mujer trabajadora (art. 18.1 CE) en tanto no decida lo contrario. Es decir, la trabajadora puede comunicar o no su estado de embarazo porque pertenece al ámbito del derecho a su intimidad. Ahora bien, si opta por no comunicar su estado, y hay un desconocimiento real por parte del empresario, no

\footnotetext{
${ }^{23}$ STC $124 / 2009$, de 18 de mayo.

${ }^{24}$ SSTS de 17 de octubre de 2008, rec. núm. 1957/2007; de 16 de enero de 2009, rec. núm. 1758/2008; de 17 de marzo de 2009, rec. núm. 2251/2008; de 13 de abril de 2009, rec. núm. 2351/2008.

${ }^{25}$ STS de 28 de noviembre de 2017, rec. núm. 3657/2015, que señala que "la protección de la mujer embarazada que instaura la Ley 39/1999 (...) se lleva a cabo sin establecer requisito alguno sobre la necesidad de comunicar el embarazo al empresario o de que éste deba tener conocimiento de la gestación por cualquier otra vía; es más, el ámbito temporal de la garantía, referida a "la fecha de inicio del embarazo»..., por fuerza excluye aquellos requisitos, pues en aquella fecha -a la que se retrotrae la protección- ni tan siquiera la propia trabajadora podía tener noticia de su embarazo".
} 
puede activarse la protección legal, porque no puede imputarse al empresario una nulidad (u otras responsabilidades) motivada por el incumplimiento de una prohibición (o de unos deberes) que no tenía por qué observar"26.

Es decir, estima que la clave se halla en determinar si se ha producido o no una vulneración del derecho constitucional a la no discriminación, de tal forma que, según la Ley 39/1999, no se exigía expresamente la comunicación del estado de gestación de la trabajadora al empresario, considerando como único indicio relevante el estado de gestación para fundamentar la nulidad del despido. Declara que "la protección de la trabajadora embarazada frente a despidos es, en gran medida, una versión legal de la doctrina del Tribunal Constitucional según la cual el embarazo está comprendido dentro de los supuestos de discriminación por razón de sexo"27. De ahí que se haya recurrido, en muchos casos, a diferenciar entre nulidad por discriminación y nulidad por motivos de conciliación de la vida laboral y familiar ${ }^{28}$.

Y esta es la línea que se sigue en la actualidad por la doctrina judicial, recordando que "el artículo 55.5.c) de la norma estatutaria establece una suerte de calificación objetiva del despido operado respecto de las trabajadoras después de haberse reintegrado al trabajo al finalizar los periodos de suspensión del contrato por nacimiento, adopción, guarda con fines de adopción o acogimiento, a que se refiere el artículo 45.1.d), siempre que no hubieran transcurrido más de doce meses desde la fecha del nacimiento, la adopción, la guarda con fines de adopción o el acogimiento; siempre y cuando en esos casos, no se declare la procedencia del despido por motivos no relacionados con el embarazo o con el ejercicio del derecho a los permisos y excedencia señalados"29.

\section{Extensión temporal de la protección}

La Directiva 92/85/CEE no se decantó por una técnica de protección causal frente al despido desde el inicio del embarazo hasta el fin del permiso por maternidad, sino por una

\footnotetext{
${ }^{26}$ STSJ Madrid, de 28 de enero de 2003, rec. núm. 3790/2002.

${ }^{27}$ STSJ Canarias, de 20 de febrero de 2006, rec. núm. 1192/2005. También SSTSJ Madrid, de 10 de noviembre de 2003, rec. núm. 4673/2003; Madrid, de 26 de abril 2004, rec. núm. 679/2004.

${ }^{28}$ SSTSJ País Vasco de 5 de marzo de 2002, rec. núm. 195/2002; Castilla y León, de 10 de marzo de 2004, rec. núm. 82/2004; STSJ Cataluña, de 18 de junio de 2001, rec. núm. 1979/2001; Madrid, de 10 de noviembre de 2003, rec. núm. 4673/2003; Madrid, de 26 de abril 2004, rec. núm. 679/2004; Comunidad Valenciana, de 14 de enero de 2005, rec. núm. $3157 / 2004$.

${ }^{29}$ STS Castilla y León, de 2 de octubre de 2019, rec. núm. 1332/2019. Así también SSTSJ Castilla y León, de 24 de junio de 2019, rec. núm. 1039/2019; País Vasco, de 12 de junio de 2018, rec. núm. 1028/2018; Cataluña, de 1 de junio de 2018, rec. núm. 6470/2015; País Vasco, de 13 de marzo de 2018, rec. núm. 194/2018. Esta última indica que "aún así, deviene interesante precisar que la Sala es conocedora no solo de la doctrina del TC (sentencia del TC 92/08) del carácter automático de la declaración de nulidad en el supuesto de que el despido no justificado de la trabajadora se produzca estando la misma gestante, aunque el empleador no tenga conocimiento del embarazo, sino que quiere reseñar que precisamente ese conocimiento o desconocimiento, deviene en estos momentos irrelevante (y mucho menos en el supuesto de autos en el que se descubre el específico conocimiento, según los hechos probados 3 y 5), por cuanto la doctrina constante, a partir de las sentencias del TS de 16-1-09, 17-3-09, 13-4-09 , 30-4-09, 6-5-09, 18-4 - 11, 25-1-13, 14-1-15 y, finalmente, 28-11-17, recurso 3657/15 , han venido insistiendo en la corrección de aquel inicial criterio al respecto, desde la referencia de la sentencia del TS de 17-10-08, recurso 1957/07, para advertir la nulidad del despido que se otorga con independencia del conocimiento por parte del empleador de la situación de gravidez".
} 
protección puramente temporal, durante el período de referencia. Para la protección desde el punto de vista de la causa se halla la Directiva 76/207/CEE y su subsiguiente Directiva 2006/54/CE que trata de evitar la discriminación de la mujer en las condiciones de trabajo. La Directiva 92/85/CE, a diferencia de las anteriores, no configura una protección basada en los motivos o razones, sino en el ámbito temporal, esto es, desde el inicio del embarazo hasta el final del permiso por razones vinculadas a la conciliación de la vida laboral y familiar.

Por tanto, dentro de este plazo, se debe proteger el despido de las trabajadoras, salvo, como ya se ha indicado, que concurran motivos justificados y objetivos, motivos establecidos por la legislación interna de cada Estado miembro, en función de las "tradiciones jurídicas" de cada uno ${ }^{30}$. En definitiva, esta protección es a plazo y no causal, pues así se deduce de la doctrina judicial comunitaria ${ }^{31}$, donde se deniega la protección, al amparo del art. 10 Directiva 92/85/CEE, a una mujer que se había sometido a un tratamiento de fecundación artificial, pero que, cuando le preavisan el despido, todavía no estaba embarazada puesto que no se le habían implantado en el útero los óvulos fecundados, aunque sí se le había practicado la denominada punción folicular. El TJUE hace referencia expresa al hecho de que la protección de la norma nace, precisamente, con el comienzo del embarazo, pues señala que "del decimoquinto considerando de la Directiva 92/85 se desprende que la prohibición de despido establecida en el artículo 10 de esta última tiene por objeto evitar que el riesgo de ser despedida por motivos relacionados con su estado pueda tener consecuencias perjudiciales sobre la salud física y psíquica de la trabajadora embarazada. En estas circunstancias, es evidente, como señaló, por su parte, el Gobierno austriaco, que la fecha que debe tenerse en cuenta para garantizar la seguridad y la protección de las trabajadoras embarazadas es la fecha más precoz posible de la existencia de un embarazo. No obstante, aun suponiendo, por lo que respecta a una fecundación in vitro, que dicha fecha sea la de la transferencia de los óvulos fecundados al útero de la mujer, por razones derivadas de la observancia del principio de seguridad jurídica, no cabe admitir que la protección establecida por el artículo 10 de la Directiva 92/85 se extienda a una trabajadora cuando, en el momento en que se le comunica su despido, aún no ha tenido lugar la transferencia de los óvulos fecundados in vitro a su útero".

De esta forma, el dies a quo se sitúa en la fecha más temprana posible de existencia del embarazo ${ }^{32}$. A partir de entonces, la trabajadora está cubierta por el art. 10 Directiva. Así lo estima también nuestra doctrina judicial ${ }^{33}$ al declarar que "es obvio que quien está bajo un tratamiento de FIV no está en situación de embarazo, pero es probable que lo esté si tal tratamiento prospera, por lo que su despido en tal situación puede considerarse discriminatorio por razón de género, pues el embarazo que se pretende es una

\footnotetext{
${ }^{30}$ CABEZA PEREIRO, Jaime (s.d.), “Sobre la tutela automática de la mujer embarazada frente al despido”. https:// xenero.webs.uvigo.es/profesorado/jaime_cabeza/embarazada.pdf

${ }^{31}$ STJUE de 26 de febrero de 2008, C-506/2006, asunto Mayr.

${ }^{32}$ En el asunto Mayr (STJUE de 26 de febrero de 2008, C-506/2006) el TJUE introduce importantes aclaraciones sobre el comienzo del embarazo a la luz de los tratamientos de reproducción asistida, donde considera que el bien jurídico que protege la Directiva es la salud de la mujer, por lo que la fecha del embarazo debe considerarse como la más temprana posible.

${ }^{33}$ STSJ Cataluña, de 5 de abril de 2019, rec. núm. 30/2019.
} 
circunstancia biológica exclusiva de la mujer". De igual forma, se interpreta en relación con el embarazo ectópico ${ }^{34}$, situación que también debe quedar protegida pues se considera que "la realidad biológica diferenciada de la constatación médica de la existencia de un embarazo ectópico, que puede diferenciarse de la realidad de un plausible embarazo ordinario o común, con estado futuro de parto o alumbramiento, no puede dejar de relacionarse como única situación protegida, desmereciendo la presente, por cuanto creemos que la vulneración del derecho fundamental a la no discriminación por razón de género, también engarza con esta realidad médica y patológica, lo más cercana al embarazo, gravidez y otros, por mucho que se paute un tratamiento de aborto bioquímico, o la prestación específica que se relacione como riesgo durante el embarazo, maternidad u otras, y tan solo haya postulado una prestación de IT por enfermedad común".

Por lo que se refiere al dies ad quem, a priori, debe señalarse que el art. 8 Convenio núm. 183 OIT regula una propuesta muy favorable, ya que no sólo prohíbe al empresario que despida a una mujer embarazada o durante el período de maternidad, sino también después de haberse reintegrado al trabajo, eso sí, durante un período que ha de determinarse en la legislación nacional.

De hecho, el legislador europeo intentó mejorar la situación de la mujer trabajadora en base a estas previsiones de la OIT, pues en la propuesta de Directiva por la que se modifica la Directiva 92/85/CEE, de 3 de octubre de 2008, se quería aumentar la duración del permiso de maternidad hasta 18 semanas, seis de las cuales debían tomarse después del parto.

De cualquier forma, debe entenderse que la interpretación restrictiva por parte del empresario de que la prohibición del despido se limite a un período concreto puede llevar a una distorsión de los derechos reconocidos a las mujeres por la Directiva. El peligro de tal distorsión se pone de manifiesto por la doctrina judicial comunitaria ${ }^{35}$ cuando indica que la prohibición de despido no se limita a la notificación de la decisión de despido durante el período de referencia, sino que también excluye tanto la adopción de tal decisión y los actos preparatorios del despido como la búsqueda y previsión de un sustituto definitivo de la empleada de que se trate. En efecto, un empresario que decide sustituir a una trabajadora embarazada que haya dado luz o se encuentre en el período de lactancia a causa de su estado, y que toma iniciativas concretas para su sustitución desde el momento en que tiene conocimiento de su embarazo, persigue el objetivo que prohíbe la Directiva 92/85/ $\mathrm{CEE}^{36}$. Asimismo, señala ${ }^{37}$ que el art. 10 Directiva 92/85 debe interpretarse en el sentido de que prohíbe no solamente notificar una decisión de despido a causa del embarazo o del nacimiento de un hijo, durante el periodo de protección tantas veces aludido (inicio del embarazo hasta el final del permiso de maternidad), sino también adoptar medidas preparatorias de tal decisión antes de expirar dicho período. Una decisión de despido a causa del embarazo o del nacimiento de un hijo es contraria al art. 2 Directiva 76/207/ CEE, cualquiera que sea el momento en que se notifique esa decisión de despido e incluso

\footnotetext{
${ }^{34}$ STS País Vasco, de 13 de marzo de 2018, rec. núm. 194/2018.

${ }^{35}$ STJUE de 11 de octubre de 2007, C-460/2006, asunto Paquay.

${ }^{36}$ NÚÑEZ-CORTÉS CONTRERAS, Pilar (2017) La maternidad. Nuevas realidades... op. cit. p. 77.

${ }^{37}$ STJUE de 11 de octubre de 2007, rec. núm. 460/2006, asunto Paquay.
} 
si se notifica una vez finalizado el período de protección establecido en el art. 10 Directiva 92/85/CEE. Dado que tal decisión de despido es contraria tanto al art. 10 Directiva 92/85/CEE, como al art. 2 Directiva 76/207/CEE, la medida elegida por un Estado miembro para sancionar la infracción de estas decisiones debe ser equivalente a la establecida por el Derecho nacional en aplicación de los arts. 10 y 12 Directiva 92/85/CEE.

Por tanto, y a la luz del actual art. 55.5 ET, debe entenderse que la fecha de inicio de la protección se sitúa desde la fecha del embarazo, debiéndose situar éste en aquel posible inicio en caso de fecundación in vitro, y en cuanto a su finalización, el citado precepto lo extiende hasta los doce meses siguientes al parto, adopción o acogimiento. Con la reforma llevada a cabo por el RDL 6/2019, la prohibición de despido se conecta con el período de tiempo comprendido entre el comienzo del embarazo hasta el final del permiso por nacimiento y cuidado del menor, concretamente, hasta los doce meses posteriores a la fecha del nacimiento, la adopción, la guarda con fines de adopción o el acogimiento. Así lo ha señalado también la doctrina judicial al declarar nulo el despido efectuado por una empresa "de quien se encontraba en el periodo de doce meses a que se refiere el artículo 55.5.c) transcrito; sin que conste practicada diligencia alguna encaminada a constatar la realidad de tal situación más allá del propio informe"38.

Considero totalmente adecuada la línea judicial que aboga por extender este período hasta incluso después de la reincorporación de la persona trabajadora, cuando existe una conexión temporal clara entre la reincorporación y el despido. De esta forma, cuando el despido se produce a los pocos días de la reincorporación del descanso por nacimiento y cuidado del menor (antigua maternidad y/o paternidad), sin que exista una fundamentación objetiva y clara, debe entenderse también como nulo, pues "y es que si bien la instancia no ha otorgado credibilidad al razonamiento de indicio de proximidad de la trabajadora demandante (8 días después de transcurridos los nueve meses reglados y objetivos), esta Sala puede afirmar que tal circunstancia probada, y al margen de la consideración objetiva que ciertamente no reconocemos, sí provoca la figura indiciaria por proximidad y cercanía (lo mismo podría argumentarse en conductas distantes para supuestos de garantía de indemnidad en relación a denuncias o quejas y sus cronologías; o en supuestos de libertad sindical para con las fechas y plazos de duración y/o agotamiento de la representación garantía laboral). Cree esta Sala que la realidad diferenciada de la circunstancia de género no discutida, unida al supuesto cercano a la protección objetiva, debe llevar aparejado un halo de indicio para con el supuesto de autos, que a su vez exige la inversión de la carga probatoria para con la empresarial, que no queda enervada del esfuerzo protocolario para demostrar la causalidad plasmada en la carta de despido, sino que, al contrario su conducta procesal debe ser exquisita e interesada al objeto de evidenciar su justificación y razonabilidad en el tipo de causalidad disciplinaria invocada, debiendo en el caso de autos esforzarse por la búsqueda de datos y consideraciones que demuestren al juzgador la ideación de la disminución voluntaria y continuada del rendimiento de la trabajadora"39.

\footnotetext{
${ }^{38}$ STSJ Castilla y León, de 2 de octubre de 2019, rec. núm. 1332/2019.

${ }^{39}$ STSJ País Vasco, de 5 de febrero de 2019, rec. núm. 74/2019.
} 
En definitiva, en función de los tres apartados del citado precepto, para el primer caso, el período temporal protegido es el que transcurre durante el embarazo, es decir, desde el comienzo del embarazo hasta el inicio del período de suspensión del contrato de trabajo por nacimiento y cuidado del menor o riesgo durante el embarazo. En palabras del $\mathrm{TS}^{40}$, el despido de la trabajadora durante el embarazo se considera un supuesto particular de despido discriminatorio. En el segundo supuesto, el período temporal de protección abarca los períodos de suspensión del contrato de trabajo por maternidad, paternidad, adopción o acogimiento, riesgo durante el embarazo, riesgo durante la lactancia natural y enfermedades causadas por embarazo, parto o lactancia natural. El tercero de los períodos objeto de protección abarca el disfrute de los permisos previstos en el artículo 37.4, 5 y 6 ET, es decir, permisos y reducciones de jornada por lactancia, nacimiento de hijos prematuros o que por cualquier causa deban permanecer hospitalizados a continuación del parto, guarda legal de un menor o discapacitado, o cuidado de un familiar, y las excedencias del artículo 46.3 ET, es decir, por cuidado de hijos o familiares. Finalmente, se protege a los trabajadores con posterioridad al término de los períodos de suspensión del contrato de trabajo por maternidad, adopción o acogimiento o paternidad, siempre que no hubieran transcurrido más de doce meses desde la fecha de nacimiento, adopción o acogimiento del hijo.

\section{Conclusión}

La prohibición de discriminación por razón de sexo tiene su razón de ser en la voluntad de terminar con la histórica situación de inferioridad, en la vida social y jurídica, de la mujer ${ }^{41}$, cualificándose la conducta discriminatoria por el resultado peyorativo para la mujer que la sufre, que ve limitados sus derechos o sus legítimas expectativas por la concurrencia de un factor cuya virtualidad justificativa ha sido expresamente descartada por la Constitución, dado su carácter atentatorio a la dignidad del ser humano. Este tipo de discriminación no comprende sólo aquellos tratamientos peyorativos que encuentren su fundamento en la pura y simple constatación del sexo de la persona perjudicada. También engloba estos mismos tratamientos cuando se funden en la concurrencia de condiciones o circunstancias que tengan con el sexo de la persona una relación de conexión directa e inequívoca. Tal sucede con el embarazo, elemento o factor diferencial que, en tanto que hecho biológico incontrovertible, incide de forma exclusiva sobre las mujeres ${ }^{42}$.

Estos supuestos de nulidad asociados a la suspensión del contrato por nacimiento y cuidado del menor, riesgo para el embarazo, adopción o acogimiento, a despidos de trabajadoras embarazadas o de trabajadores en situación de excedencia por cuidado de hijos, o que estén disfrutando de los referenciados permisos, no se configuran legalmente como supuestos asimilados a la nulidad por invocación de una vulneración de derechos fun-

\footnotetext{
${ }^{40}$ STS de 19 de julio de 2006, rec. núm. 387/2005.

${ }^{41}$ STC $17 / 2003$, de 30 de enero.

${ }^{42}$ SSTC 173/1994, de 7 de junio; 20/2001, de 29 de enero; 41/2002, de 25 de febrero; 17/2003, de 30 de enero; 98/2003, de 2 de junio; 175/2005, de 4 de julio; 214/2006, de 3 de julio; 342/2006, de 11 de diciembre.
} 
damentales, sino que este supuesto anuda de manera automática a la decisión extintiva empresarial la nulidad de la misma siempre que se acredite la realidad de la situación protegida y la ausencia de una causa empresarial suficiente que justifique la extinción.

De esta forma, se podría indicar que nuestro ordenamiento jurídico ofrece dos vías de protección por razón del embarazo. Una primera vía, objetiva y automática, a través del art. 55.5 b) ET, basada en el embarazo y con independencia de su conocimiento por el empresario y que opera durante toda la relación laboral, incluido el período de prueba ${ }^{43}$. En este caso basta la prueba del embarazo por la trabajadora, debiendo entonces probar el empresario una causa objetiva y razonable para el desistimiento, prueba que de producirse comportará la declaración de procedencia o de licitud del desistimiento, en caso contrario, la nulidad será la consecuencia. Una segunda vía, mediante el art. 55.5.1 ET, antidiscriminatoria, que requiere la existencia de un acto de discriminación por razón de sexo perpetrado por el empresario y que también opera durante toda la relación laboral, incluido el período de prueba. En este caso, la trabajadora ha de aportar indicios suficientes de que su despido o cese se debe a la discriminación por embarazo, mientras que sobre la empresa recae la carga de probar la ausencia de discriminación en las medidas adoptadas y su proporcionalidad.

En suma, queda claro que la normativa y la doctrina sigue avanzando en pro de la tutela de la mujer trabajadora y la protección de la familia y los hijos, pero siguen existiendo reticencias por parte de los empresarios sobre la colocación de mujeres trabajadoras que, por su perfil, puedan ser futuras madres.

\section{Bibliografía}

ARAMENDI SÁNCHEZ, Pablo (2006) El despido de la trabajadora embarazada. Un análisis de la Sentencia de 19 de julio de 2007 del Pleno de la Sala IV Tribunal Supremo, $A S$, núm. 13 (versión on line).

ARGÜELLES BLANCO, Ana Rosa (1998) La protección de intereses familiares en el ordenamiento laboral. Valencia: Tirant lo Blanch, 1998.

DE LA VILLA GIL, Luis Enrique; GARCÍA NINET, Ignacio; NOGUEIRA GUASTAVINO, Magdalena; MORÓN PRIETO, Ricardo; DE LA VILLA DE LA SERNA, Diego (1998), Leyes Sociales Internacionales y Comunitarias. Madrid: CEURA.

CABEZA PEREIRO, Jaime (s.d.), Sobre la tutela automática de la mujer embarazada frente al despido. https://xenero.webs.uvigo.es/profesorado/jaime_cabeza/embarazada.pdf

CORDERO SAAVEDRA, Luciano (2002), La protección de las mujeres embarazadas contra el despido y aplicación de las directivas 76/207/CEE Y 92/85/CEE (A propósito de la STJCE 4 de octubre de 2001), Aranzadi Social, núm. 5, 2002.

ELORZA-GUERRERO, Fernando (2010), Despido y prueba de la discriminación indirecta por razón de sexo, TL, núm. 103, 2010.

${ }^{43}$ STSJ Andalucía, de 19 de octubre de 2010, st. núm. 2795/2010. 
GIL PLANA, Juan (2012) La nulidad del despido de la trabajadora embarazada, REDT, núm. 154 (versión on line)

LOUSADA AROCHENA, José Fernando (2000) Las novedades en el régimen de los permisos parentales introducidos en la Ley 39/1999, de 5 de noviembre, $A L$, núm. 25.

MAZUELOS FERNÁNDEZ-FIGUEROA, Manuel (2002), Alcance del efecto directo del artículo 10 de la directiva 92/85/CEE ante el incumplimiento de un Estado miembro: Crónica de una cuestión prejudicial: protección del despido de las mujeres embarazadas y la sentencia del Tribunal de Justicia de 4 de octubre de 2001, Actualidad Jurídica Aranzadi, núm. 520, 2002.

MELLÁ MÉNDEZ, Lourdes (Coord.) (2015), Conciliación de la vida laboral y familiar y crisis económica: estudios desde el derecho internacional y comparado. Madrid: Delta Publicaciones Universitarias.

MOLINA GONZÁLEZ-PUMARIEGA, Rocío (2004), La protección jurídica de la mujer trabajadora. Madrid: CES.

MOLINA NAVARRETE, Cristóbal (2018), El "plus de riesgo de despido" de las mujeres embarazadas: ¿"indemnización disuasoria” también para la nulidad objetiva? Comentario a la Sentencia del Tribunal Supremo 942/2017, de 28 de noviembre, RTSS, núm. 421, 2018.

NÚÑEZ-CORTÉS CONTRERAS, Pilar (2017) La maternidad. Nuevas realidades en el Derecho de la Unión Europea. Madrid: Dykinson.

RUBIO DE MEDINA, Maㅡ Dolores (2006) El despido de la mujer embarazada. Barcelona: Bosch.

SÁNCHEZ- URÁN AZAÑA, Yolanda (2007) Despido y "móvil discriminatorio": garantías, sustantiva y procesal, tras la Ley Orgánica para la Igualdad Efectiva de Mujeres y Hombres, $A L$, núm. 14, 2007. 